\title{
Pembelajaran interaktif melalui game edukatif selama masa pandemi di TK Al Ghifari Bandung
}

\author{
Vera Suryani*, Bayu Erfianto, Andrian Rakhmatsyah, Fazmah Arif Yulianto \\ Fakultas Informatika, Universitas Telkom \\ Email Korespondensi: *verasuryani@telkomuniversity.ac.id
}

Received June 18, 2021; Revised July 9, 2021; Accepted July 23, 2021

\begin{abstract}
Abstrak
Kurikulum sekolah TK meliputi aspek motorik,maupun kognitif bagi anak usia pra-sekolah. Pembelajaran daring selama pandemi membuat anak cepat bosan, karena masa konsentrasi mereka belum bisa lama seperti halnya orang dewasa. Dibutuhkan perangkat bantu agar penyampaian materi lebih menarik dan tidak membosankan. Permainan merupakan salah satu cara penyampaian materi agar anak TK dapat belajar secara menyenangkan. Game edukatif merupakan perangkat bantu yang bersifat menarik bagi anak TK, dan melalui game ini materi pembelajaran dapat disampaikan secara menarik. Tujuan kegiatan pengabdian masyarakat ini ialah melakukan penyuluhan kepada guru PAUD TK Al-Ghifari Sukabirus mengenai cara penyampaian materi pembelajaran melalui game edukatif, serta pelatihan kepada anak TK mengenai cara penggunaan game edukatif tersebut. Game edukatif bertujuan untuk meningkatkan motivasi belajar melalui story telling, peningkatan konsentrasi, serta aspek computational thinking untuk usia pra-sekolah. Dari hasil pelaksanaan kegiatan pengabdian masyarakat di TK Al Ghifari Bandung di dapatkan bahwa perangkat dan modul pembelajaran yang diberikan sangat membantu proses belajar mengajar di TK Al Ghifari. Poin utama yang disasar adalah aspek motivasi dan konsentrasi anak usia TK.
\end{abstract}

Kata Kunci: TK Al Ghiffari; game edukatif; motivasi; konsentrasi

\begin{abstract}
Kindergarten school curriculum covers motor and cognitive aspects for preschoolers. Online learning might make the children bored quickly, because their concentration period is shorter than adults. Assistive devices are needed so that the delivery of material is more interesting and not boring. Games are one way of delivering material so that kindergarten children can learn in a fun way. Learning aids in the form of games, of course, must adapt to online conditions during the pandemic. Educational games are tools that are interesting for kindergarten children, and through these games learning materials can be presented in an interesting way. The purpose of this community service activity is to provide training to TK Al-Ghifari Sukabirus teachers on how to deliver learning materials through educational games. Educational games aim to increase motivation to learn through story telling, increase concentration, and aspects of computational thinking for preschoolers. From the results of the implementation of community service activities at Al Ghifari Kindergarten in Bandung, it was found that the learning tools and modules provided greatly helped the teaching and learning process at Al Ghifari Kindergarten. The main development points targeted in this activity are the motivation and concentration aspects of preschoolers age.
\end{abstract}

Keywords : Al Ghifari Kindergarten; educational games; motivation; concentration

\section{PENDAHULUAN}

Pendidikan anak-anak masa golden age (1 s.d 5 tahun) merupakan tahapan yang sangat penting bagi anak. Pada masa tersebut diperlukan stimulasi yang sesuai agar anak tumbuh kembang anak menjadi optimal. Beberapa stimulasi yang dapat diberikan antara lain: perkembangan motorik halus, motorik kasar, kognitif, dan optimalisasi potensi anak lainnya [1]-[3]. Sekolah Pendidikan Anak Usia Dini (PAUD) dan Taman KanakKanak (TK) merupakan salah satu tempat bagi anak untuk mendapatkan stimulasi yang tepat sesuai perkembangannya. Hal ini didukung oleh Pemerintah melalui PP No. 27 Tahun 1990.

Selama masa pandemi Corona, proses pembelajaran dialihkan menjadi daring. Tak terkecuali anak PAUD dan TK. Kondisi yang berbeda ini tentu saja berakibat pada proses delivery materi sekolah yang berbeda pula. Guru dituntut untuk kreatif dan atraktif dalam penyampaian materi sekolah selama daring [4]. Game edukatif bisa menjadi salah satu pilihan untuk penyampaian materi [5]-[9][10]. Mengingat banyak aspek yang harus dikembangan untuk usia pra-sekolah, dalam kegiatan pengabdian masyarakat hanya berfokus pada aspek peningkatan konsentrasi, motivasi belajar, dan computational thinking. Beberapa persyaratan penunjang kegiatan ini antara lain adalah siswa sebaiknya tidak buta warna, dan telah dikondisikan sebelumnya oleh guru. Kegiatan pengkondisian ini lebih bersifat bermain untuk proses pengeluaran energi berlebih pada anak, selain 
untuk transisi adaptasi kegiatan dari rumah ke sekolah.

\section{METODE}

Pelaksanaan pengabdian masyarakat dilakukan secara onsite dan daring. Penyerahan dan pemeriksaan kualitas perangkat dilakukan secara onsite, sedangkan pelatihan game edukatif dilakukan secara daring. Kegiatan yang dilaksanakan ini merupakan hasil analisis dari permasalahan serta kebutuhan dari TK Al Ghifari. Analisis yang dilakukan berdasarkan diagram fishbone sebagaimana terlihat pada Gambar 1.

\section{Diagram Fishbone Kegiatan PkM}

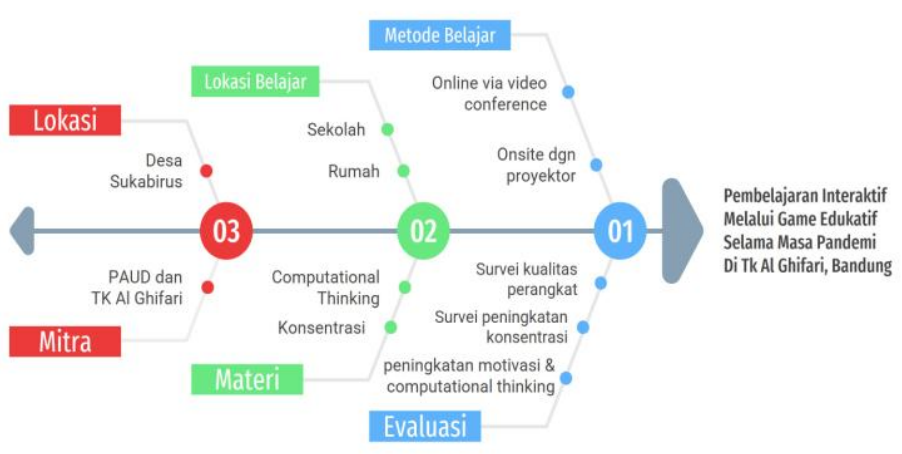

Gambar 1. Diagram Fishbone Kegiatan PkM

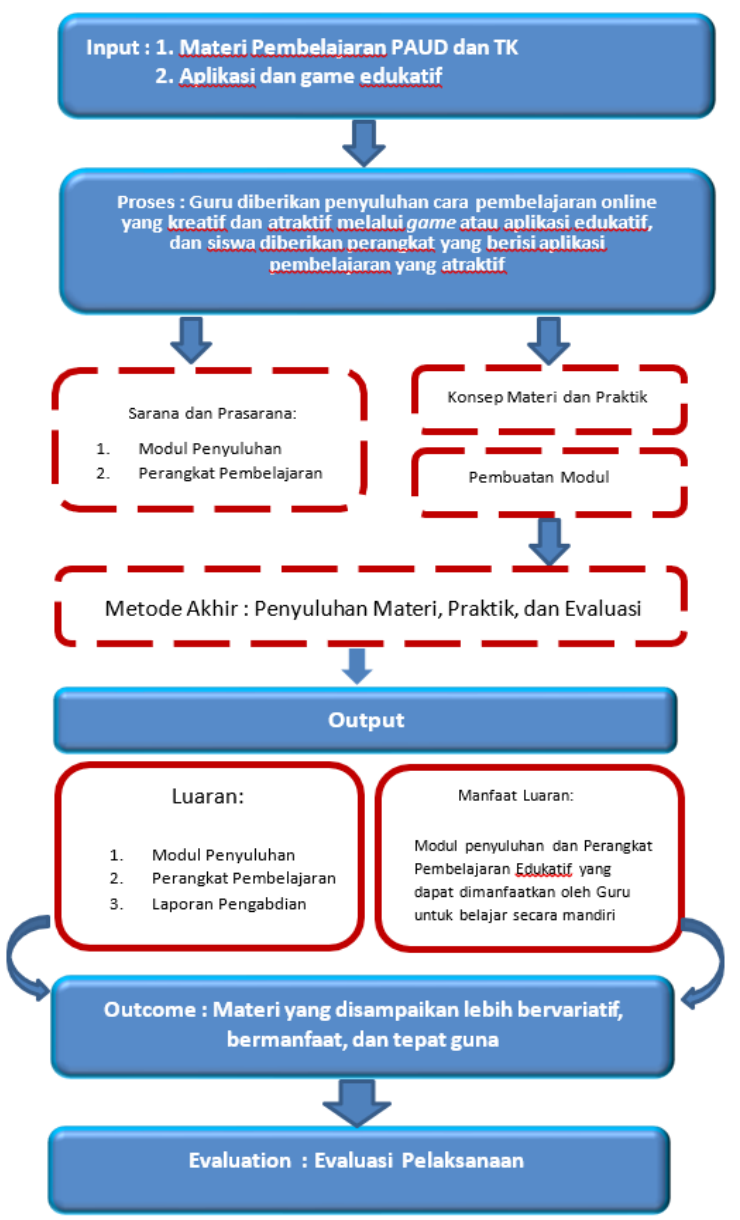

Gambar 2. Gambaran Iptek yang Disalurkan

Dalam kegiatan ini dilaksanakan dalam 3 (tiga) metode yaitu :

a. Penyuluhan kepada guru RA Al-Ghifari Sukabirus mengenai cara pembelajaran online yang kreatif dan atraktif melalui game atau aplikasi edukatif lainnya

b. Pelatihan kepada murid RA Al-Ghifari Sukabirus mengenai cara pemakaian aplikasi edukatif atau 
game dengan muatan pendidikan.

\section{c. Evaluasi Pelaksanaan}

Kegiatan pengabdian masyarakat dilaksanakan secara bertahap dalam waktu 6 bulan. Bulan pertama melakukan survey dan komunikasi dengan mitra dalam rangka user requirement. Bulan kedua dan ketiga melakukan penyusunan modul, mekanisme praktik dan model pembelajaran sesuai user requirement. Bulan kelima melakukan penyuluhan metode pembelajaran jarak jauh. Bulan keenam melakukan evaluasi kegiatan dan penyusunan laporan. Adapun luaran IPTEK dari kegiatan ini dapat dilihat pada Gambar 2. Luaran IPTEK ini bertujuan sebagai quality control terhadap proses dan luaran yang dihasilkan dalam kegiatan pengabdian masyarakat.

\section{HASIL DAN PEMBAHASAN}

Kegiatan di awali dengan penyerahan media pembelajaran dan modul pelatihan, sebagaimana terlihat pada Gambar 3. Kegiatan berikutnya ialah melakukan penyuluhan kepada guru PAUD TK Al-Ghifari Sukabirus mengenai cara penyampaian materi pembelajaran melalui game edukatif. Melalui penyuluhan dan pelatihan ini, dapat membantu guru TK Al Ghifari terkait proses pembelajaran yang interaktif, melalui permainan edukatif dan murid TA dapat belajar secara menyenangkan.

Materi yang disampaikan meliputi permainan yang bisa dimunculkan dari media yang sudah diberikan. Sebagai contoh permainan untuk meningkatkan motivasi belajar, konsentrasi, dan computational thinking untuk usia pra-sekolah. Kegiatan penyuluhan dan pelatihan dilakukan secara daring, memanfaatkan aplikasi zoom meeting. Adapun dokumentasi penyuluhan pembelajaran interaktif melalui aplikasi edukatif dapat ditemukan pada Gambar 3.
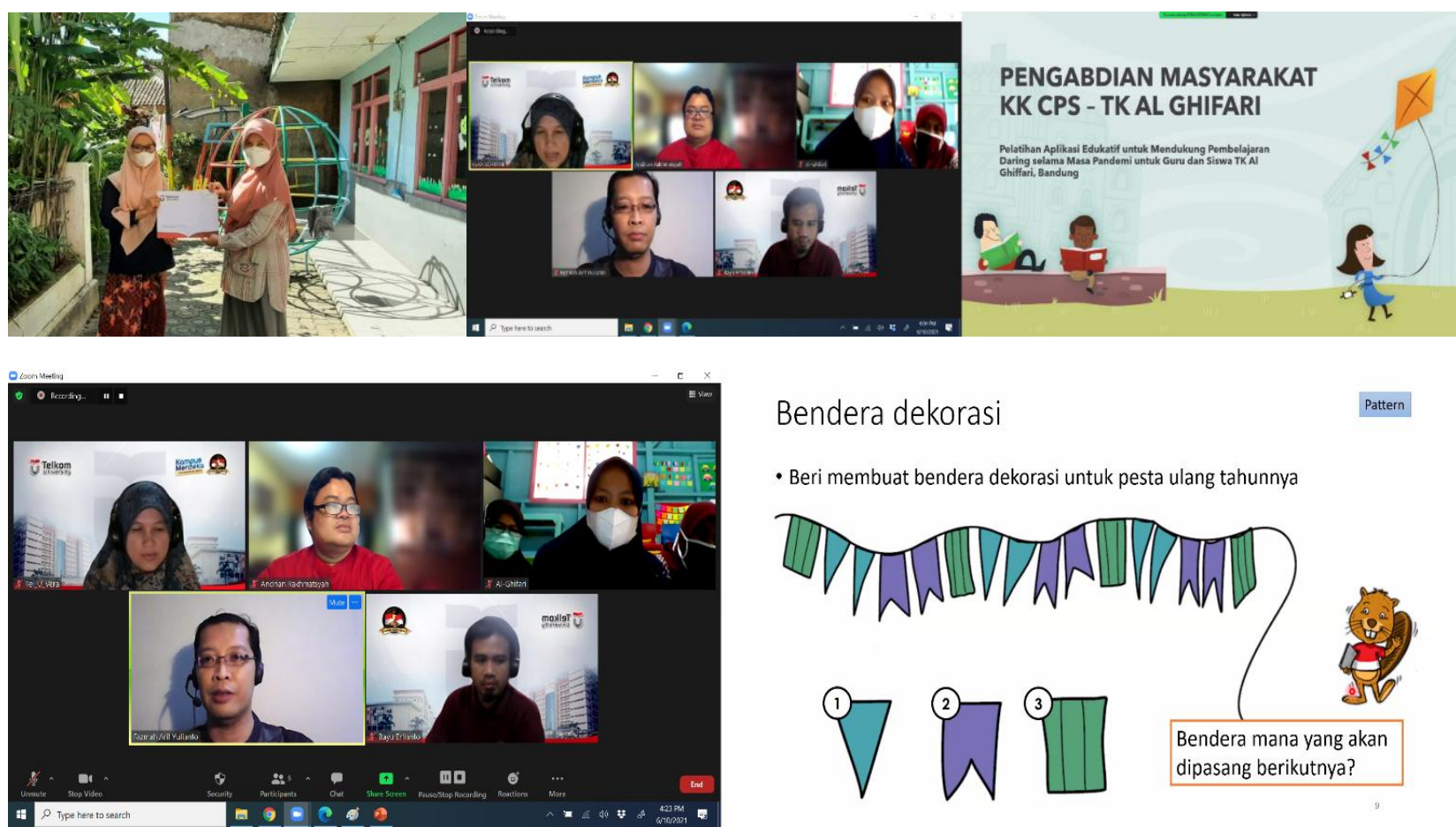

Bendera dekorasi

- Beri membuat bendera dekorasi untuk pesta ulang tahunnya

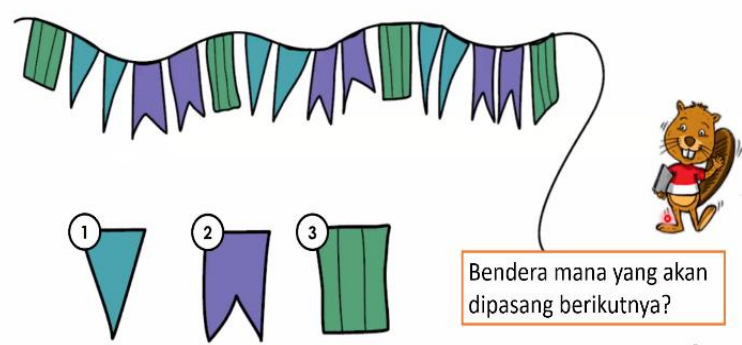

Gambar 3. Dokumentasi Kegiatan Penyuluhan Pembelajaran Interaktif Melalui Aplikasi Edukatif

Setelah dilakukan penyuluhan dan pelatihan kepada guru, berikutnya dilakukan survei. Responden dari survei adalah guru TK yang telah diberi pelatihan, serta murid yang diwakili orangtuanya dalam mengisi survei. Isi survei meliputi kemudahan penggunaan media pembelajaran, pengaruh game edukatif terhadap peningkatan motivasi belajar dan konsentrasi terutama materi computational thinking. Tak lupa survei mengenai kepuasan mitra terhadap pelaksanaan kegiatan pengabdian masyarakat. Pelaksanaan survei bertujuan untuk mengevaluasi metode yang digunakan dalam kegiatan ini. 


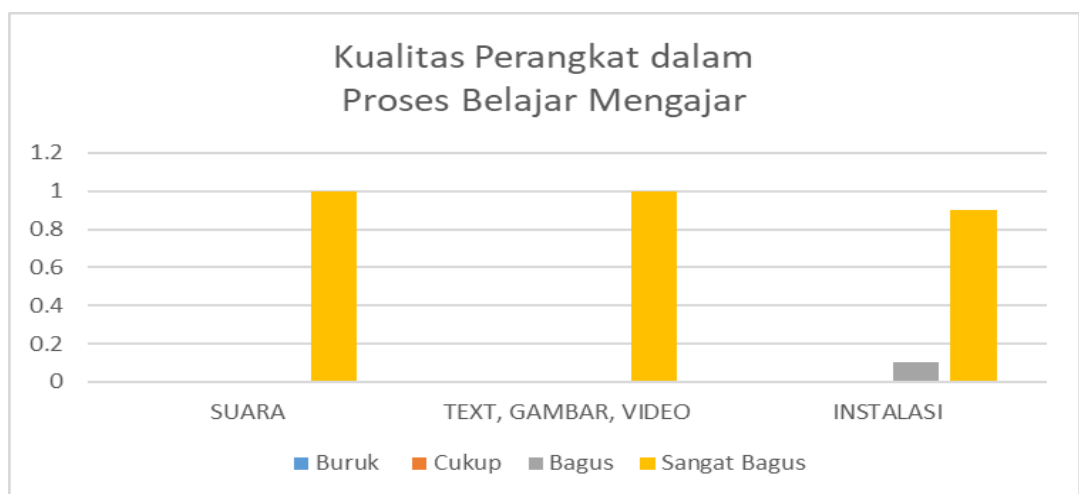

Gambar 4. Persentase Kepuasan Guru terhadap Kualitas Perangkat

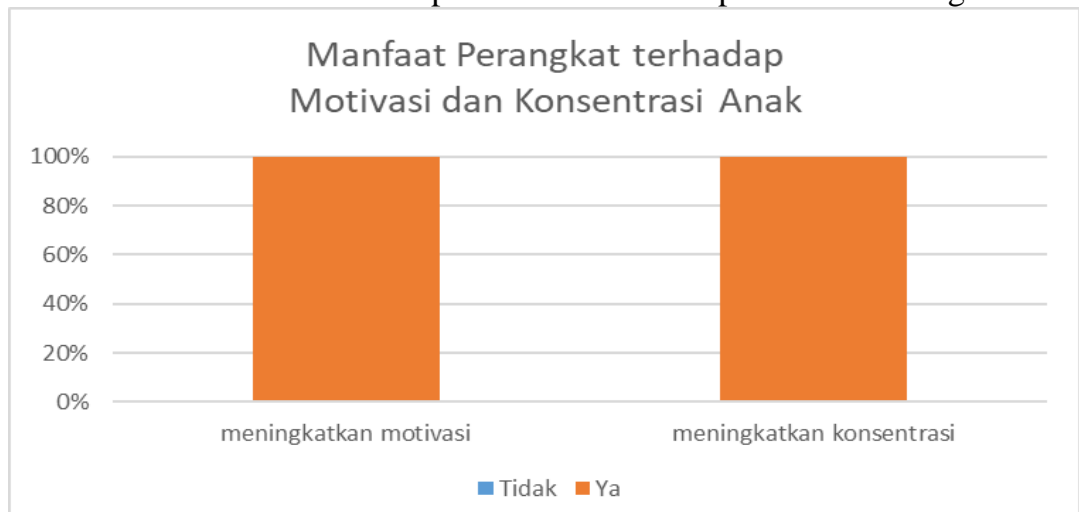

Gambar 5. Persentase Kepuasan Guru terhadap Peningkatan Motivasi dan Konsentrasi Belajar

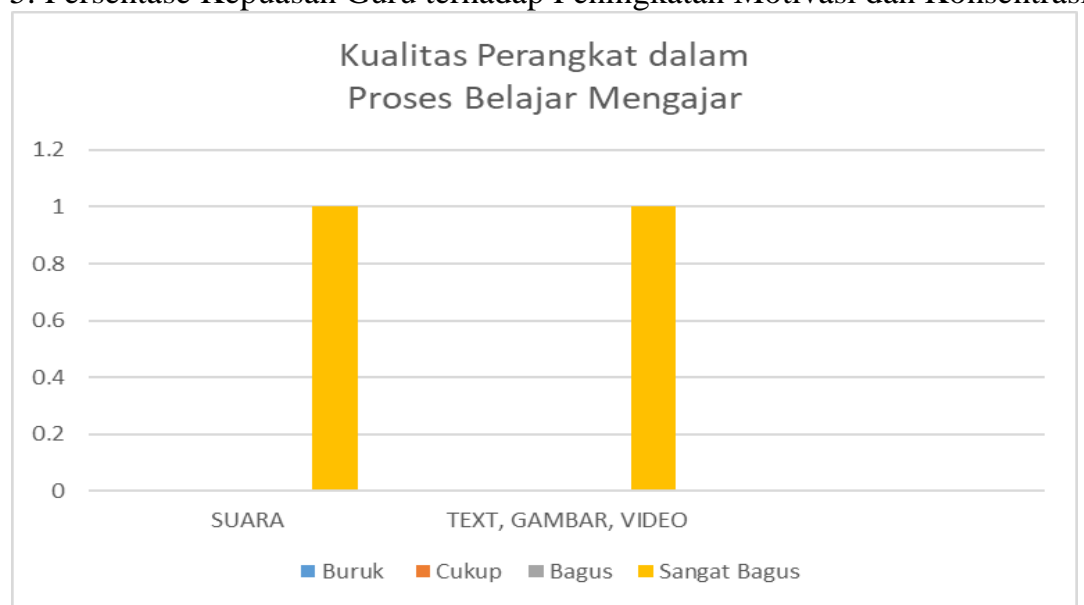

Gambar 6. Persentase Kepuasan Murid terhadap Kualitas Perangkat

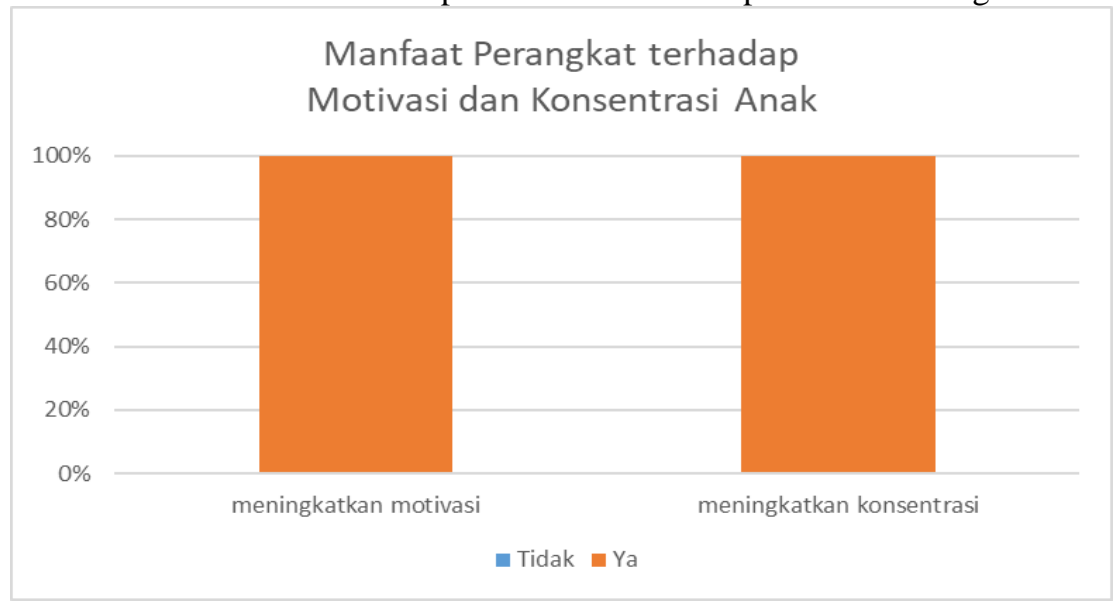

Gambar 7. Persentase Kepuasan Murid terhadap Peningkatan Motivasi dan Konsentrasi Belajar 
Gambar 4 s.d 7 merupakan hasil survey terhadap kualitas perangkat serta hasil survey pengaruh perangkat terhadap motivasi dan konsentrasi anak oleh user Guru TK dan Anak TK (diwakilkan oleh orangtua). Selain survei terkait media dan penyuluhan yang diberikan, dilakukan pula survei kepuasan mitra pengabdian masyarakat. Hasil survei dapat dilihat pada Tabel 1.

Tabel 1. Hasil Survey Kepuasan Mitra PkM

\begin{tabular}{|c|c|c|c|c|c|}
\hline \multirow[t]{2}{*}{ Penilaian Terhadap Kegiatan } & \multicolumn{4}{|c|}{ Jumlah masing-masing Faktor yang Dipentingkan } & \multirow[b]{2}{*}{ Total } \\
\hline & $\begin{array}{c}\text { Sangat Tdk } \\
\text { setuju }\end{array}$ & Tdk Setuju & Setuju & $\begin{array}{l}\text { Sangat } \\
\text { setuju }\end{array}$ & \\
\hline 1. Sesuai dengan tujuan & 0 & 0 & 2 & 12 & 14 \\
\hline 2. Sesuai dengan kebutuhan & 0 & 0 & 1 & 13 & 14 \\
\hline 3. Waktu memenuhi kebutuhan & 0 & 0 & 5 & 9 & 14 \\
\hline 4. Ramah, cepat tanggap & 0 & 0 & 2 & 12 & 14 \\
\hline $\begin{array}{l}\text { 5. Menerima dan mengharapkan } \\
\text { pengmas }\end{array}$ & 0 & 0 & 1 & 13 & 14 \\
\hline Jumlah & 0 & 0 & 11 & 59 & 70 \\
\hline Persentase & $0 \%$ & $0 \%$ & $16 \%$ & $84 \%$ & \\
\hline Jumlah $\%$ setuju + sangat setuju & & & & $100 \%$ & \\
\hline
\end{tabular}

Dari hasil survey didapatkan kesimpulan bahwa tingkat kepuasan mitra PkM terhadap pembelajaran interaktif melalui aplikasi edukatif sangat memuaskan. Hal ini membuka kesempatan untuk tindak lanjut kegiatan PkM lain yang sesuai dengan kebutuhan mitra.

\section{KESIMPULAN}

Kegiatan pengabdian kepada masyarakat ini dapat memberikan manfaat kepada guru TK Al Ghifari terkait proses pembelajaran yang interaktif, melalui permainan edukatif. Kegiatan ini juga dapat mempermudah guru penyampaikan materi kepada anak TK secara menyenangkan.

\section{DAFTAR PUSTAKA}

[1] Barno A, Yokutkhon I, Feruzaxon Y, and Makhliyo I, "Methodology of Using Game Technologies in Preschool Education," Int. J. Adv. Sci. Technol., vol. 29, no. 7, pp. 2242-2245, 2020.

[2] N. Li, "Study on the Interaction between Music and Games in Preschool Music Education," in 2nd International Conference on Education, E-learning and Management Technology, 2017, pp. 214-218.

[3] R. I. Borman and I. Erma, "Pengembangan Game Edukasi Untuk Anak Taman Kanak-Kanak (Tk) Dengan Implementasi Model Pembelajaran Visualitation Auditory Kinestethic (Vak)," JIPI (Jurnal Ilm. Penelit. dan Pembelajaran Inform., vol. 3, no. 1, pp. 8-16, 2018.

[4] V. D. Wicaksono and P. Rachmadyanti, "Pembelajaran Blended Learning melalui Google Classroom di Sekolah Dasar,” in Seminar Nasional Pendidikan PGSD UMS \& HDPGSDI Wilayah Timur, 2016, pp. 513-521.

[5] A. Epriliyansyah et al., "Perancangan Game Edukasi Pengenalan Perhitungan Untuk Anak Usia Dini Dengan Metode RAD Berbasis Android," J. FTIK, vol. 1, no. 1, pp. 629-638, 2018.

[6] Andri Setiawan, Henry Praherdhiono, and Sulthoni, "Penggunaan Game Edukasi Digital Sebagai Sarana Pembelajaran Anak Usia Dini,” J. Inov. Teknol. Pembelajaran, vol. 6, no. 1, pp. 39-44, 2019.

[7] A. V. Vitianingsih, "Game Edukasi Sebagai Media Pembelajaran PAUD,” J. Inf., vol. 1, no. 1, pp. 1-8, 2016.

[8] D. L. Fithri and D. A. Setiawan, "Analisa Dan Perancangan Game Edukasi Sebagai Motivasi Belajar Untuk Anak Usia Dini," Simetris J. Tek. Mesin, Elektro dan Ilmu Komput., vol. 8, no. 1, pp. 225-230, 2017.

[9] Sri Lestari R and Fujiati, "Penerapan Game Design Document dalam Perancangan Game Edukasi yang Interaktif untuk Menarik Minat Siswa dalam Belajar Bahasa Inggris," J. Teknol. Inf. dan Ilmu Komput., vol. 5, no. 3, pp. 341-346, 2018.

[10] M. Nurhayati, "Penggunaan Media Audio Visual LCD Proyektor Pada Anak Kelompok A TK Dharma Wanita Semanding Pagu Kediri Tahun Pelajaran 2015 / 2016," UNIVERSITAS NUSANTARA PGRI KEDIRI, 2016. 
